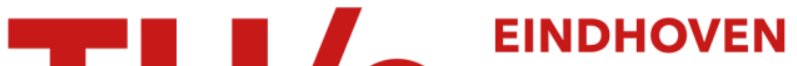

\section{Optimization of a Convex Rail Design for Electromagnetic Launchers}

Citation for published version (APA):

Polat, H., Tosun, N., Ceylan, D., \& Keysan, O. (2020). Optimization of a Convex Rail Design for Electromagnetic Launchers. IEEE Transactions on Plasma Science, 48(6), 2266-2273. [9104009].

https://doi.org/10.1109/TPS.2020.2993785

\section{Document license:}

TAVERNE

DOI:

10.1109/TPS.2020.2993785

Document status and date:

Published: 01/06/2020

\section{Document Version:}

Publisher's PDF, also known as Version of Record (includes final page, issue and volume numbers)

\section{Please check the document version of this publication:}

- A submitted manuscript is the version of the article upon submission and before peer-review. There can be important differences between the submitted version and the official published version of record. People interested in the research are advised to contact the author for the final version of the publication, or visit the $\mathrm{DOI}$ to the publisher's website.

- The final author version and the galley proof are versions of the publication after peer review.

- The final published version features the final layout of the paper including the volume, issue and page numbers.

Link to publication

\section{General rights}

Copyright and moral rights for the publications made accessible in the public portal are retained by the authors and/or other copyright owners and it is a condition of accessing publications that users recognise and abide by the legal requirements associated with these rights.

- Users may download and print one copy of any publication from the public portal for the purpose of private study or research.

- You may not further distribute the material or use it for any profit-making activity or commercial gain

- You may freely distribute the URL identifying the publication in the public portal.

If the publication is distributed under the terms of Article $25 \mathrm{fa}$ of the Dutch Copyright Act, indicated by the "Taverne" license above, please follow below link for the End User Agreement:

www.tue.nl/taverne

Take down policy

If you believe that this document breaches copyright please contact us at:

openaccess@tue.nl

providing details and we will investigate your claim. 


\title{
Optimization of a Convex Rail Design for Electromagnetic Launchers
}

\author{
Hakan Polat, Nail Tosun ${ }^{\circledR}$, Doğa Ceylan ${ }^{\circledR}$, and Ozan Keysan ${ }^{\circledR}$
}

\begin{abstract}
A rail geometry with a convex cross section instead of a rectangular one provides a higher contact area, uniform current density, and less transition on the contact surface, and it increases the performance in electromagnetic launchers. In addition, the design of convex rails should be considered together with armature structure, the distance between rails, rail length, and parasitic masses that all have an influence on the overall efficiency and armature/rail transition. A novel complete rail and launch package optimization method is presented in this article. In the first part of this article, the optimum convex rail cross sections for five different separation values are found to obtain uniform current density distribution on rail cross section. For this part, a transient finite element (FE) model in 2-D is developed to calculate the current density distribution and combined with a real-coded genetic algorithm (GA). Then, the armature and sabot petal masses are calculated for each optimized rail geometry and each separation values. In the second part, the efficiency of each optimum design with different separation values is evaluated by a transient 3-D FE model with transient solver taking the calculated armature and sabot petal masses into account. Finally, the length of the rails of the final design is investigated for the transition phenomena. It is observed that $48-\mathrm{mm}$ rail separation with 12.9- and 21-mm elliptical cross-sectional parameters has the highest exit velocity $(2355 \mathrm{~m} / \mathrm{s})$ for $400-\mathrm{g}$ projectile with uniform current density at inner rail surfaces.
\end{abstract}

Index Terms-Convex rails, electromagnetic launch (EML), finite element (FE) analysis, genetic algorithm (GA), pulsed power supply, railgun.

\section{INTRODUCTION}

$\mathbf{E}$ LECTROMAGNETIC launcher (EML) is an electromechanical energy conversion device that converts electrical energy into linear mechanical energy. An EML consists of basically two parallel conducting rails, a conducting armature, and a nonconductive projectile, which keeps the projectile in place during launch called sabot petals. EMLs are excited by pulse power supplies (PPSs), which can supply a pulse-shaped current with a peak value in the mega-amperes (MA) range. This current creates a large amount of magnetic field between the rails. Because of Lorentz force acting on the armature, launch packages can be accelerated to a few thousand $\mathrm{m} / \mathrm{s}$.

Manuscript received October 21, 2019; revised March 13, 2020 and May 2, 2020; accepted May 4, 2020. Date of publication May 29, 2020; date of current version June 10, 2020. This work was supported in part by ASELSAN Inc. and in part by PARGE. The review of this article was arranged by Senior Editor F. Hegeler. (Corresponding author: Ozan Keysan.)

The authors are with the Department of Electrical and Electronics Engineering, Middle East Technical University, 06800 Ankara, Turkey (e-mail: keysan@metu.edu.tr).

Color versions of one or more of the figures in this article are available online at http://ieeexplore.ieee.org.

Digital Object Identifier 10.1109/TPS.2020.2993785
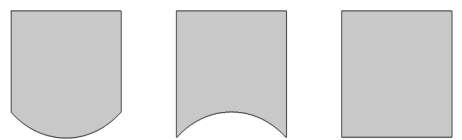

Convex Rails Concave Rails Rectangular Rails
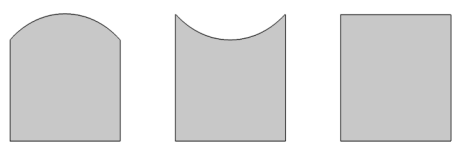

Fig. 1. Different rail geometries that are often investigated in the literature.

In [1]-[4], it is discussed that there exist three different rail geometries: flat, concave, and convex rails as shown in Fig. 1. Although the flat bore rail provides larger inductance gradient $\left(L^{\prime}\right)$ than the convex and concave ones as explained in [4], the convex-shaped rails are superior to the flat and concave surfaced rails in terms of their larger contact area [5], more uniform current [3]-[5], and therefore a better heat distribution [6]. Moreover, since $L^{\prime}$ is directly related to the Lorentz force acting on the armature as given in (1), the increase in $L^{\prime}$ may be the primary target to optimize the railgun shape

$$
F_{\text {lorentz }}=\frac{1}{2} L^{\prime} I^{2} \text {. }
$$

However, maximizing $L^{\prime}$ can be misleading for the optimization studies of railguns. Although large separation increases $L^{\prime}$, it also increases the parasitic mass, total mass excluding the projectile, which may decrease the overall system efficiency, as in (2). $E_{\text {muzzle }}$ is the muzzle kinetic energy of the launch package, $E_{\mathrm{PPS}}$ is the total PPS energy, $m_{\text {projectile }}$ is the mass of the launch package, and $v_{\text {exit }}$ is the muzzle velocity of the projectile

$$
\eta=\frac{E_{\text {muzzle }}}{E_{\text {PPS }}}=\frac{m_{\text {projectile }} v_{\text {exit }}^{2}}{2 E_{\mathrm{PPS}}} .
$$

Barber et al. [7] explained that transition in solid armature railguns, which results in a sudden increase in the muzzle voltage, may occur due to several reasons, such as loss of contact, magnetic sawing, mechanical fracture, and magnetic blow off ext. Since transition leads to melting and corrosion on the rails, it decreases the performance of the launch and lifetime of the rails. Zhang et al. [8] also explained that high currents at the armature and rail interface may cause local hot spots, which leads to material loss, melting, and transition. Electrical erosion in the rails and armature is proportional to the square of the current as explained in [9]. On the one hand, 


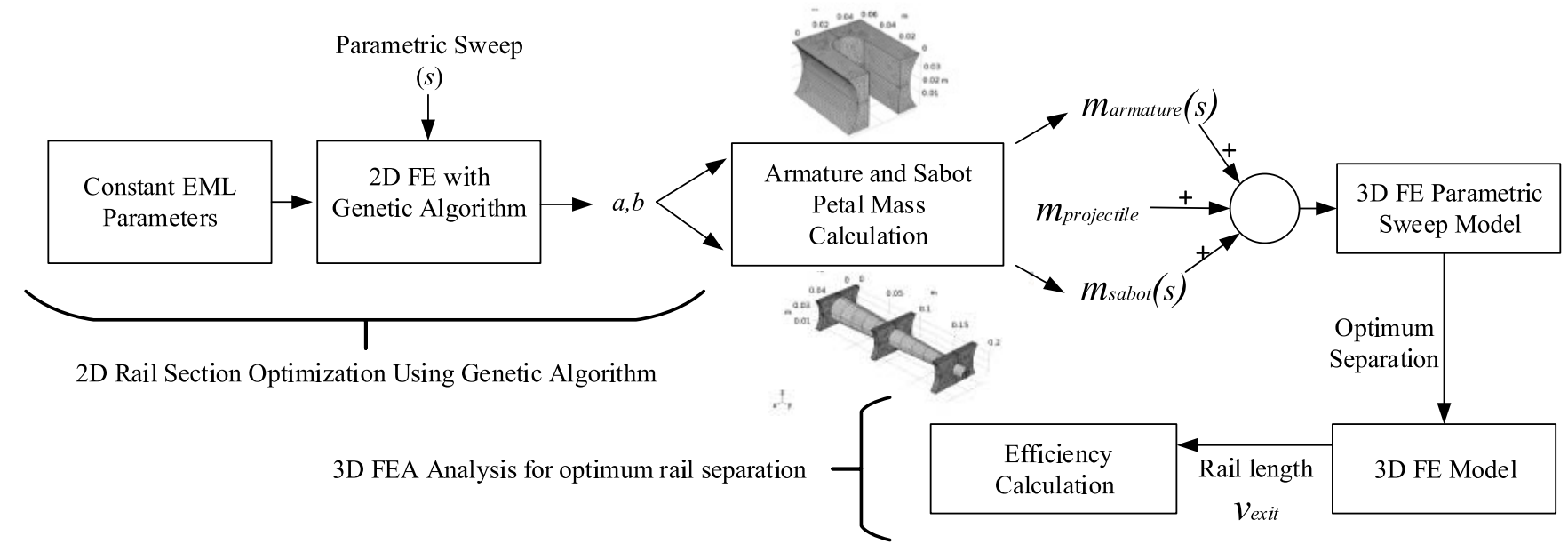

Fig. 2. Optimization flowchart.

TABLE I

EML SYSTEM CONSTANTS

\begin{tabular}{lc}
\hline Projectile Mass & $400 \mathrm{~g}$ \\
Rail Height & $40 \mathrm{~mm}$ \\
Rail Width & $40 \mathrm{~mm}$ \\
Armature Height & $40 \mathrm{~mm}$ \\
Pre-load Distance & $50 \mathrm{~cm}$ \\
Minimum Rail Separation & $40 \mathrm{~mm}$ \\
Maximum Rail Separation & $80 \mathrm{~mm}$ \\
Linear Current Density & $35 \mathrm{kA} / \mathrm{mm}$ \\
Peak Current & $1400 \mathrm{kA}$ \\
\hline
\end{tabular}

TABLE II

Properties of Armature and Rail Materials

\begin{tabular}{llll}
\hline & $\sigma(\mathrm{MS} / \mathrm{m})$ & $\rho\left(\mathrm{kg} / \mathrm{m}^{3}\right)$ & $\mathrm{C}_{\mathrm{p}}(\mathrm{J} /(\mathrm{kgK}))$ \\
\hline Armature & 19.2 & 2700 & 900 \\
Rails & 43.5 & 8960 & 385 \\
\hline
\end{tabular}

the larger current leads to more Lorentz force on the armature and projectile. On the other hand, high currents can damage rails and armature. Therefore, preventing high current density spots on the contact surface between the rails and armature is crucial for EML design.

\section{System CONSTANTS AND Limitations}

The initial selection of EML system constants is crucial for the overall design. The selected parameters are given in Table I. These constant parameters are taken from the PEGASUS Railgun project that is presented in [10]. Also, in [11], it is recommended to choose a linear current density between 30 and $43 \mathrm{kA} / \mathrm{mm}$ to decrease the transition possibility. Choosing a linear current density higher than $43 \mathrm{kA} / \mathrm{mm}$ for rectangular rails almost results in transition during launch. However, for convex rails, this limitation is unknown and beyond the scope of this article. Armature height is taken equal to the height of the rails in order to maximize the contact area between rails and armature. After determining the rail height, the linear current density is chosen as $35 \mathrm{kA} / \mathrm{mm}$. Using the determined rail height and linear current density, the peak value of the excitation current is calculated as $1400 \mathrm{kA}$. The rail and armature materials relevant to the study are listed in Table II. According to [12], the transition occurs at the downslope of the current waveform when the current is lower than $80 \%$ of the peak current due to the reversed magnetic forces acting on the wings of the C-shaped armatures. In order to prevent the transition, the launch package should leave the rails before the current drops to $80 \%$ of its peak value. Therefore, the rail length is selected using the velocity and current graphs to ensure this condition.

\section{Aim And Methodology of the Proposed Study}

In this article, the aim is to find the optimum shape of the rails with the most suitable separation value for a $400-\mathrm{g}$ projectile and a constant excitation current waveform with 1400-kA peak value. In Fig. 2, the overall flowchart of the study is presented. Mainly, it consists of two parts: the rail geometry optimization for different separation values and the calculation of maximum exit velocity. The output of the first part is used as the input of the second part. In the first part, a real-coded genetic algorithm (GA) is developed to find the optimum shape of the convex rails for five different separation values: $40,50,60,70$, and $80 \mathrm{~mm}$. In this part, the objective function is the uniformity of the current density distribution on the contact surface between the rails and the armature. Since the rail cross-sectional geometry is selected as elliptic, the search space of the optimization problem also includes the circular convex rail geometries. The outputs of this part are two geometric parameters, which define the convexity of rails, and the mass of the armature and sabot for each separation value. The armature and sabot petal geometries are shown in Fig. 3.

These outputs are used to calculate the maximum exit velocity. In this part, a 3-D transient finite element (FE) model is developed using COMSOL Multiphysics. The purpose of this part is to find the best design that gives the highest efficiency.

\section{Rail Geometry Cross-Sectional Optimization}

During the launch, currents up to a few MA passes through the rails and armature in a few milliseconds. Hence, skin effect and proximity effect are the most effective parameters in the current distribution for the first few milliseconds. As the 


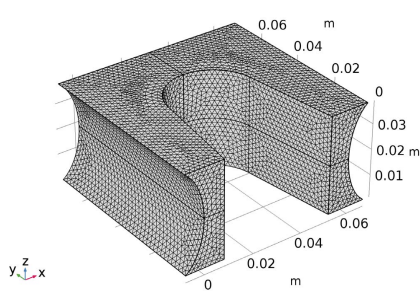

(a)

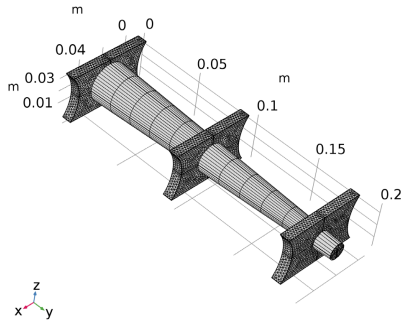

(b)
Fig. 3. Variable rail parameters. (a) C-armature geometry. (b) Sabot petal geometry.

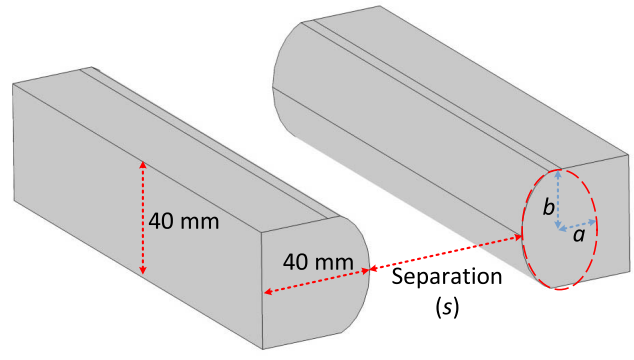

$y^{2}+x$

Fig. 4. Geometric parameters of the rail. For the armature geometry, the armature length and height are taken as constants. The projectile geometry is constant and enclosed by the sabot petals. The sabot petal geometry is modified according to separation.

speed of the armature increases, the velocity skin effect (VSE) starts to dominate the current distribution in the rails and armature. The influence of the VSE phenomenon on the current density distribution is discussed in [13]. Due to these effects, the current density increases at the trailing edge of the armature on the contact surface. Since the spots with high current densities cause transition, both reducing and flatting the current density in armature rail contact is crucial.

In order to optimize the rail geometry, a 2-D FE model is built in the COMSOL Multiphysics environment. The FE model uses the magnetic field module where a direct time-dependent solver is used. Moreover, the model is with a mesh number of around 35000. The developed quarter symmetric model is used to calculate the objective function of the proposed optimization algorithm shown in Fig. 2. The GA was implemented in MATLAB, and the FEA model is used to calculate the cost function. The optimization study is repeated for different rail separations for the further investigation of the effect of separation on the overall system efficiency. The constant rail parameters and the optimization parameters to define the convexity of the rails are presented in Fig. 4. Although in several studies [1], [2], [4], [14], the convexity of the rails is defined using the parameters of a circle, an ellipse is considered as a more general solution in this study, which also includes the circular geometries to increase the search space of the optimization study.

The optimization problem is simplified to 2-D in the $x z$ plane (i.e., infinite rail length) of Fig. 4. This approach decreases the computational cost of the optimization. Also, the skin effect and proximity effect are still considered during the calculation of the current density distribution on the rail

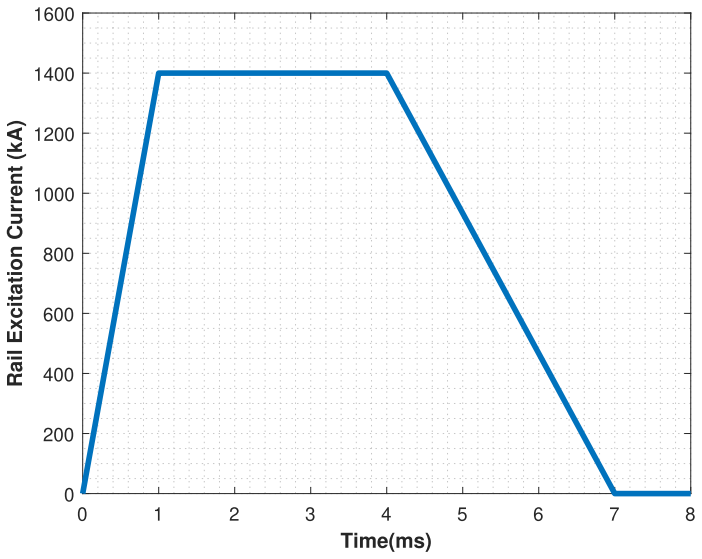

Fig. 5. Rail excitation current waveform.

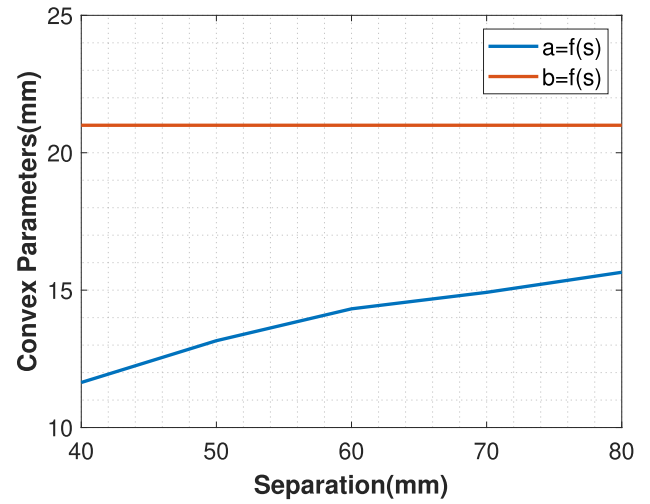

Fig. 6. Optimization results for different separation parameters.

cross section. However, this approach ignores the VSE since the direction of the armature velocity is in the $y$-direction. In the proposed 2-D FE model, rail current given in Fig. 5 is used. In order to obtain the uniform current density distribution on the armature-rail contact surface, the current ramp-up stage $(0-1 \mathrm{~ms})$ is investigated since the skin effect is the most dominant in this region. A GA is implemented to determine the convex rail parameters where the optimization algorithm has two design variables and one objective function. The objective function is to minimize $J_{\max }$ in the inner surface of the rails with adjusting the defined rail parameters: $a$ and $b$. The minimized $J_{\max }$ also reduces the ohmic losses. Hence, it is possible to achieve generating a uniform heat distribution. The optimization problem is defined as in (3). The separation is swept from 40 to $80 \mathrm{~mm}$ with $10-\mathrm{mm}$ increments. The optimum values of $a$ and $b$ for each selected separation values are presented in Table VI. Moreover, current density distribution results for 40-, 60-, and $80-\mathrm{mm}$ separations are given in Fig. 7

$$
\begin{aligned}
& \begin{array}{l}
\text { minimize } J_{\max } \\
\text { subject to } 0 \mathrm{~mm} \leq a \leq 20 \mathrm{~mm} . \\
20 \mathrm{~mm} \leq b \leq 100 \mathrm{~mm} .
\end{array} \\
& \text { V. CALCULATION OF PARASITIC MASSES } \\
& \text { FOR VARYING RAIL PARAMETERS }
\end{aligned}
$$

\section{Calculation of Parasitic Masses FOR VARYING RAIL PARAMETERS}

The launch package consists of a projectile, armature, and sabot. Sabot petals are responsible to keep the projectile in 


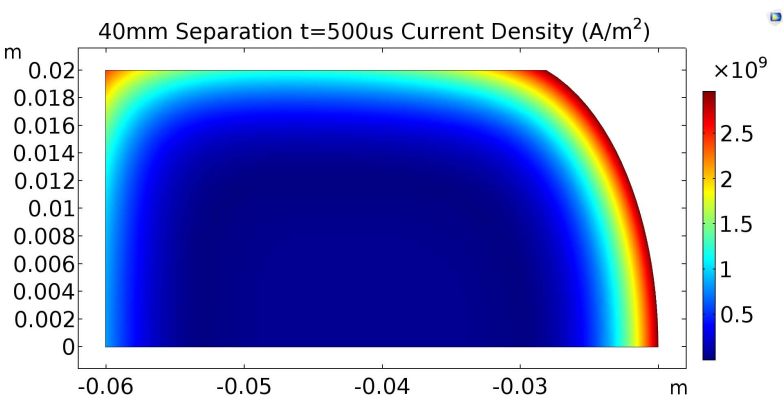

(a)

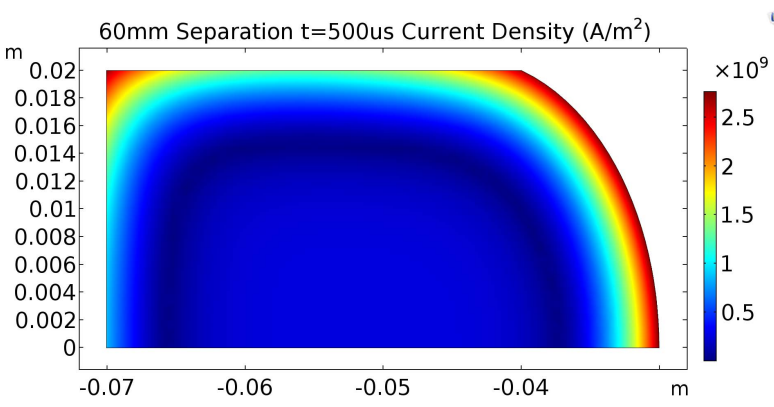

(b)

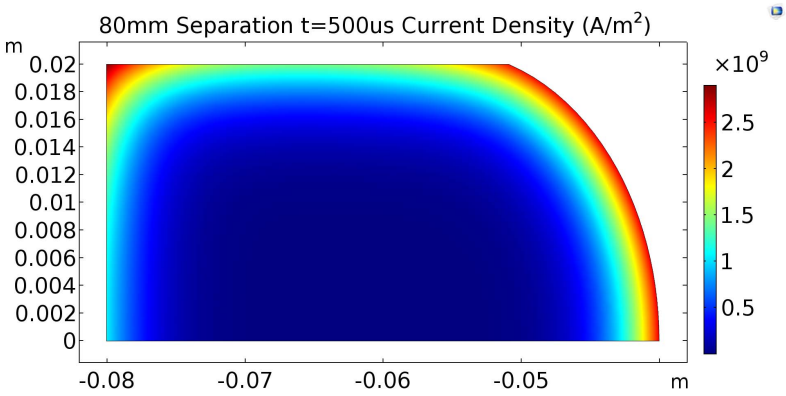

(c)

Fig. 7. Current density distribution for different separations after GA optimization. The maximum current density decreases with increase in separation due to the reduction in the proximity effect. This also results in a more circular inner rail surface. (a) $s=40 \mathrm{~mm}$. (b) $s=60 \mathrm{~mm}$. (c) $s=80 \mathrm{~mm}$.

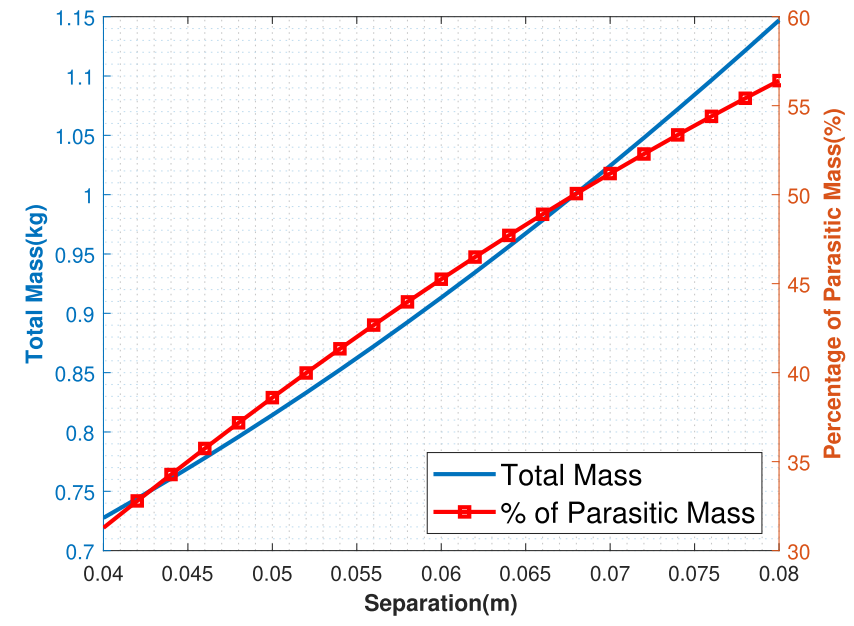

Fig. 8. Variation of total mass and parasitic mass ratio with separation.

place and keep the projectile stable during the launch. Since the primary goal of railguns is to accelerate the projectile, the other parts of the launch package, which are armature and sabot, are considered as parasitic masses.

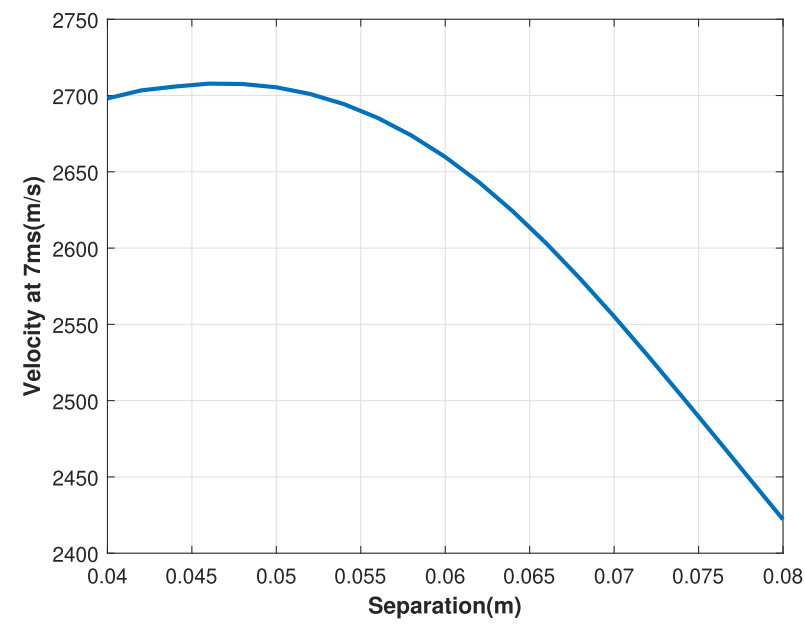

Fig. 9. Exit velocity versus separation. Using varying parasitic armature, sabot petals, and current excitation, the exit velocity of each launch package is presented.

More parasitic masses result in less acceleration. Total launch package mass calculation and acceleration are given in (6) and (7)

$$
\begin{aligned}
m_{\text {launch }} & =m_{\text {armature }}+m_{\text {sabot }}+m_{\text {projectile }} \\
a_{\text {projectile }} & =\frac{F_{\text {Lorentz }}}{m_{\text {armature }}+m_{\text {sabot }}+m_{\text {projectile }}} .
\end{aligned}
$$

The aim of this section is to determine the armature and sabot masses with varying rail parameters $a, b$, and separation. The mass of the projectile is taken as constant since our goal is to present an optimization method that maximizes overall system efficiency with a novel surface current density optimization method for small/medium caliber railguns. The geometry of the projectile is considered as conic. The optimum rail parameters for different separation values were calculated separately, as explained in Section III. Then, empiric equations of the optimum rail parameters with respect to separation are obtained. Hence, each optimum rail parameter $a$ and $b$ for different separation is known, and armature and sabot geometries can be generated. One example can be observed in Fig. 3.

\section{RESULTS}

In this part, it is aimed to find the optimum rail separation and rail length, which maximizes the projectile exit velocity. In order to find the optimum separation and rail length values, the convex rail parameters ( $a$ and $b$ ), which are found in Section IV, and corresponding parasitic masses, which is found in Section V, are used. In addition to the optimum rail separation, the rail length is also calculated in this part of the study. The rails are assumed to be infinitely long. The rails are exited with the current waveform given in Fig. 5. Then, this process is repeated for 1-mm intervals between 40- and 80-mm separation values for the launch package mass in (6) where armature and sabot petal masses are a function of rail parameters $a, b$, and $s$. Afterward, the separation that has the maximum velocity at the end of the current pulse is chosen. According to the analysis, the maximum velocity is found when $s$ is equal to $48 \mathrm{~mm}$, which is given in Fig. 9. Although 
TABLE III

EXIT Velocities AND Optimum RAIL LENGTHS FOR DIFFERENT SEPARATION VALUES

\begin{tabular}{llc}
\hline Separation(mm) & Exit Velocity $(\mathbf{m} / \mathbf{s})$ & Rail Length(m) \\
40 & 2239 & 5.04 \\
50 & 2310 & 5.24 \\
60 & 2200 & 4.94 \\
70 & 2048 & 4.60 \\
80 & 1816 & 4.18 \\
\hline
\end{tabular}

it seems choosing the rail as long as possible to minimize the muzzle current, another important criterion for the current ramp-down is the reverse-induced current on the armature due to negative $d I / d t$. The induced current in the reverse direction deflects the wings of the $\mathrm{C}$-armature, reducing the contact area and increasing the contact resistance due to lack of contact force. The rail length is chosen as $5.3 \mathrm{~m}$ that is the point where $80 \%$ of the peak current at ramp-down stage flow in the rails. Although the optimum case is found as $s=48 \mathrm{~mm}$, the exit velocity and rail length for different separations are presented in Table III. Clearly, since the current pulse is the same, the exit time of all separations is $4.6 \mathrm{~ms}$. Therefore, there is an optimum separation between 40 and $50 \mathrm{~mm}$ where the rail length is at its maximum. Similar results were previously found in Fig. 9. Since the exit velocity of $50 \mathrm{~mm}$ is higher, the rail length resulting in $80 \%$ peak current is longer than other separations.

In Section IV, the rail cross sections were modeled in 2-D and a GA was implemented in order to homogenize the current distribution in the ramp-up stage. The results for separations between 40 and $80 \mathrm{~mm}$ with $10-\mathrm{mm}$ increment are listed in 6. Although $a$ and $b$ were selected as design parameters, $b$ converged to the same result $21-\mathrm{mm}$ regardless of the separation. The optimum distribution for $40 \mathrm{~mm}$, $60 \mathrm{~mm}$, and $80 \mathrm{~mm}$ is shown in Fig. 7. In the next section, the armature and sabot geometries are generated. In Fig. 8, the total mass of the launch package and the percentage of parasitic mass (armature + sabot petals) are presented. Using a 3-D FE model, the total masses are analyzed and separation versus exit velocity is presented in Fig. 9. The separation is chosen as $48 \mathrm{~mm}$ since it has the maximum projectile exit velocity. The current distribution for optimum separation is presented in Fig. 12, which has $a=12.9 \mathrm{~mm}$ and $b=$ $21 \mathrm{~mm}$. Compared with the $40 \mathrm{~mm} \times 40 \mathrm{~mm}$ square rails, the current distribution is clearly homogenized on the inner surface. In accordance with Barber et al. [7], the rail length is chosen as $5.3 \mathrm{~m}$ since $80 \%$ of peak current is the exit current. The rail current versus rail length is presented in Fig. 10. The kinetic energies of the projectile, total mass, and exit kinetic energy utilization are shown in Fig. 11. The overall end results of convex rail optimization are listed in Table IV.

Another advantage of convex rails compared to square rails is heat distribution due to the homogenized current flowing through the conductor. As stated in Fig. 5, the launch process ends after $7 \mathrm{~ms}$. As an approximation, the heat conduction coefficient of rail material is taken as zero. Hence, the change in the temperature after the launch can be stated as in (8), where $C_{p}$ is the heat capacity, $\rho_{\text {rail }}$ is the density, and $\sigma$ is the conductivity of the rail material. The volume integral is

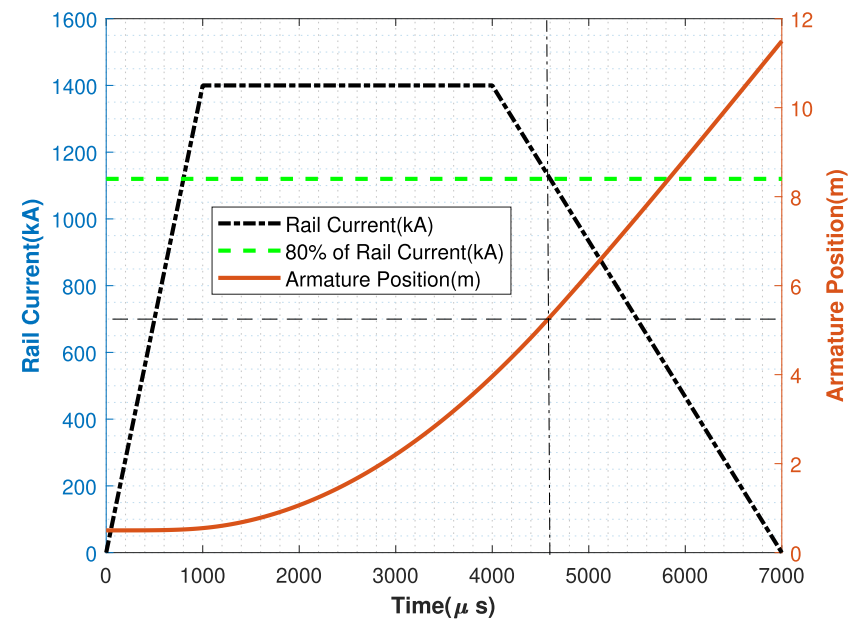

Fig. 10. Total rail length calculation. The rail length is found such that the armature exits the rails when the rail excitation current is at its $80 \%$ of its peak.

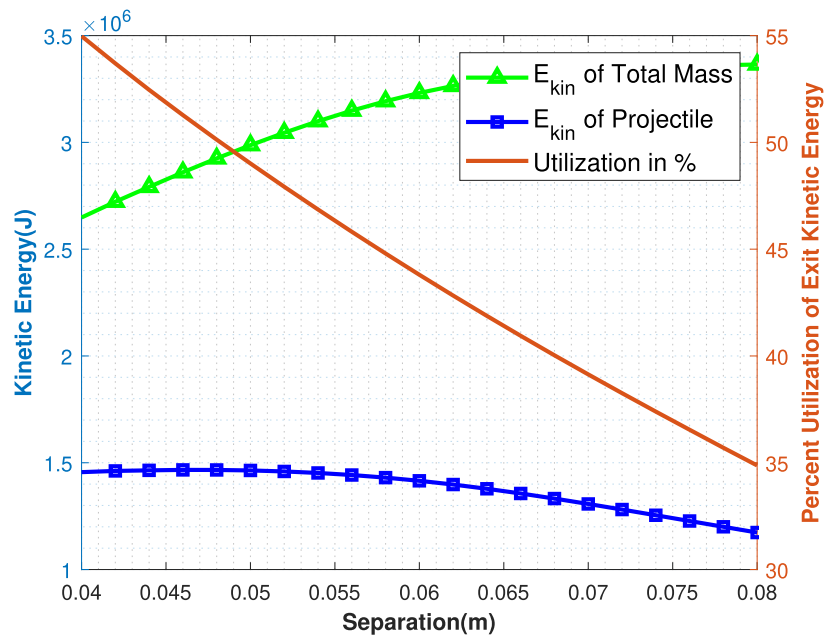

Fig. 11. Exit kinetic energy of projectile, total mass, and utilization percentage. As the separation increases, the kinetic energy of the launch package increases where the projectile kinetic energy has a maximum at $s=48 \mathrm{~mm}$.

TABLE IV

Optimized Convex Rail and OVERALl System Parameters

\begin{tabular}{lc}
\hline Total Rail Length & $5.3 \mathrm{~m}$ \\
a & $12.9 \mathrm{~mm}$ \\
b & $21 \mathrm{~mm}$ \\
Separation(s) & $48 \mathrm{~mm}$ \\
Armature mass & $182.8 \mathrm{~g}$ \\
Sabot mass & $213.1 \mathrm{~g}$ \\
Launch package mass & $796 \mathrm{~g}$ \\
Projectile Muzzle Velocity & $2355 \mathrm{~m} / \mathrm{s}$ \\
Projectile Muzzle Energy & $2.21 \mathrm{MJ}$ \\
Exit Time & $4.6 \mathrm{~ms}$ \\
\hline
\end{tabular}

taken over the preloaded rail section. $\Delta T$ is the change in temperature just after the launch. The change of temperature $(\Delta T)$ after launch is presented in Fig. 13. In the square rails, the maximum temperature change increases up to $216 \mathrm{~K}$ where, in the convex rail case, there is a uniform temperature distribution around $120 \mathrm{~K}$

$$
\Delta T=\frac{1}{C_{p} \rho_{\text {rail }} \int_{0 \mathrm{~ms}}^{7 \mathrm{~ms}} \iiint_{V} \frac{J^{2}}{\sigma} d V d t} .
$$




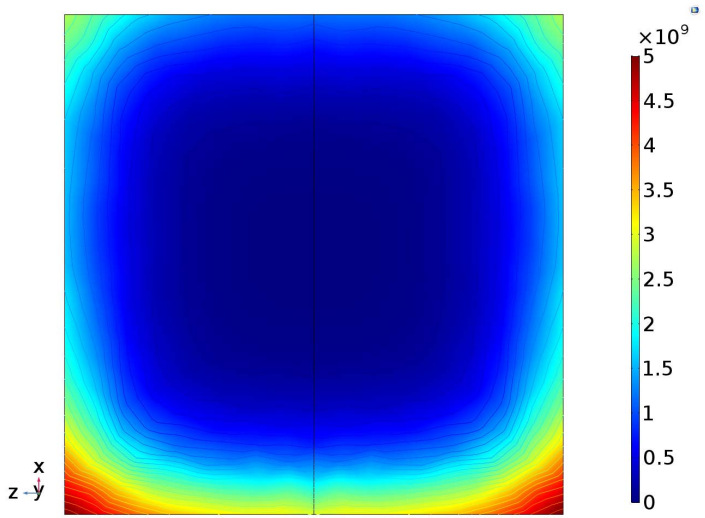

(a)

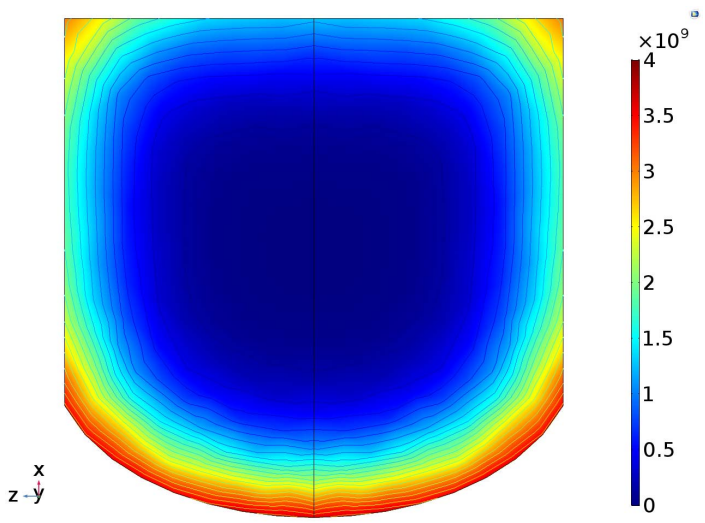

(b)

Fig. 12. $s=48 \mathrm{~mm}$ square and convex rail current distribution $\left(\mathrm{A} / \mathrm{mm}^{2}\right)$ and flux density ( $T$ ) lines. (a) 48-mm separation square rail $1000-\mu \mathrm{s}$ current distribution (A/ $\left.\mathrm{mm}^{2}\right)$ and flux density (T) lines. (b) 48-mm separation convex rail $1000-\mu$ s current distribution $\left(\mathrm{A} / \mathrm{mm}^{2}\right)$ and flux density $(T)$ lines.

\section{DISCUSSION}

In this article, a multistage optimization was performed in order to determine the convex rail parameters, including the parasitic armature and sabot petal masses. According to the study, there exits a unique " $a$ " for each different rail separation. At the end of this part, a one-to-one function of $a=f(s)$ was derived, whereas " $b$ " converged to the same value. If a single circular conductor carrying ac current is considered, the current distribution should overlap with the circular magnetic field lines. However, in EML applications due to the proximity effect, the center of the circular field lines is directly related to the separation. Moreover, the field lines are not circular. Therefore, although analytical approach provides a clear insight, a 2-D FE method (FEM) optimization is essential. Convergence of " $b$ " to $21 \mathrm{~mm}$ (the diameter is around the same as the rail height) and almost linear increase of " $a$ " with increasing rail separation show that as the separation increases, the optimum curve of the convex rails converges to a circular geometry, which overlaps with the fact that proximity effect decreases with increasing rail separation.

The first part of this was performed in 2-D FEA in order to reduce the complexity and most importantly reduce the computation time. Implementing VSE into 2-D FEA is impossible due to the 2-D geometry. The GA is not feasible with a 3-D moving armature FEA model, as it requires a high number

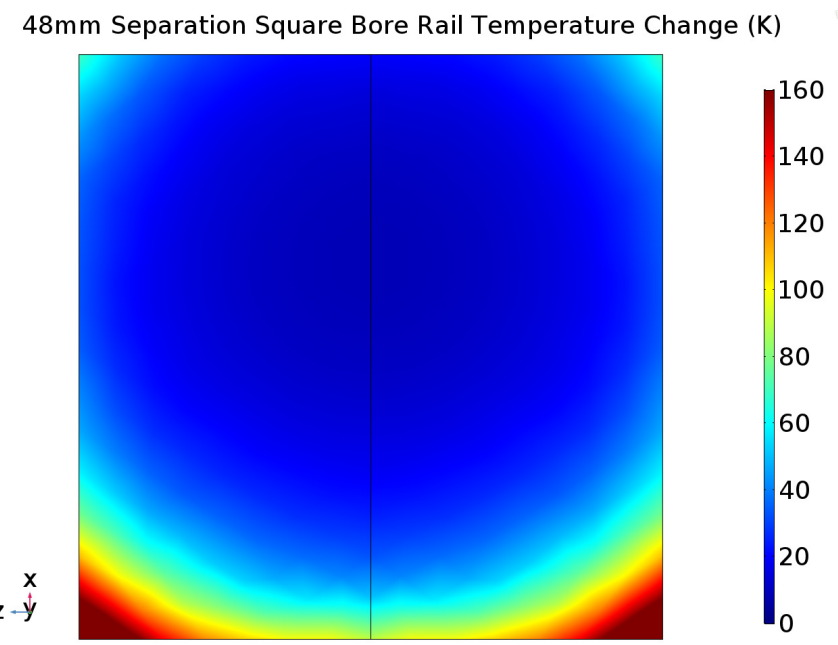

(a)

48mm Separation Convex Bore Rail Temperature Change (K)

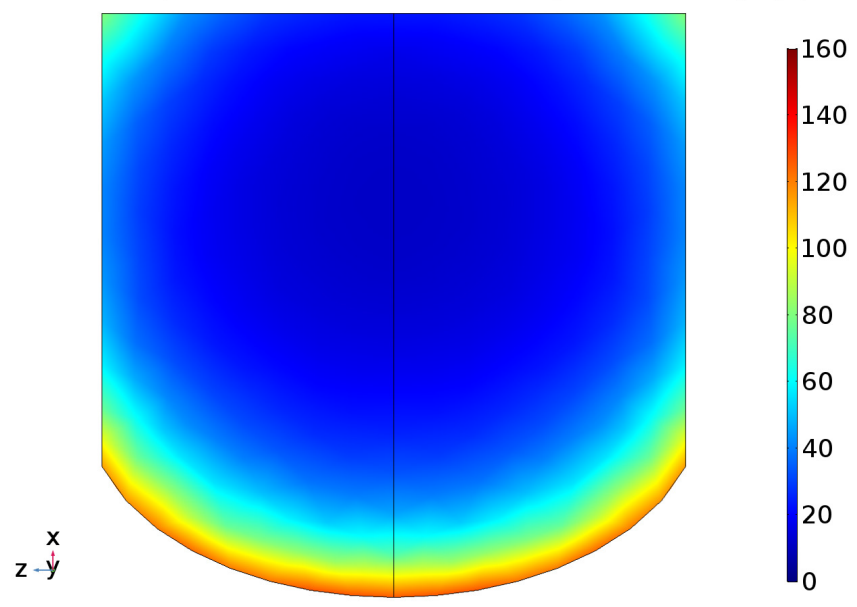

(b)

Fig. 13. Temperature increase in the rail. (a) For square cross section. (b) For convex cross section. The maximum rail temperature change occurs for square rails with $\Delta T=216 \mathrm{~K}$. In convex rails, not only the temperature change is uniform but also significantly lower with a maximum of $\Delta T=120 \mathrm{~K}$. (a) $48-\mathrm{mm}$ separation $40 \mathrm{~mm} \times 40 \mathrm{~mm}$ square rails. (b) $48-\mathrm{mm}$ separation convex rails.

of design evaluations to converge. Moreover, VSE is highly dominant close to the armature-rail contact interface. In this article, the aim is to propose a method and have the most uniform current distribution on the convex rail surface. The armature-rail contact current distribution is highly dependent on the armature design. Hence, VSE is neglected in this article. Another topic requiring further explanation is the heat distribution. In the heat calculation, the heat conduction coefficient of the rail material was assumed to be zero. This assumption is only valid to calculate the rail temperature right after the launch. Moreover, in the analysis, the current was assumed to flow through the rails all the time. However, this is only valid for the preload of the rail geometry. Considering the heat generation formula, the hottest part of the rail is also the preload position. In this article, worst case scenario was shown. Uniform current distribution in the inner rail surface clearly decreases the heat generation. Further heat generation analysis is presented in [6] and beyond the scope of this article. 
In this article, the linear current density is taken as $35 \mathrm{kA} / \mathrm{mm}$, which reduces the possibility of transition presented by the statistical study in [11]. This study was performed using rectangular caliber EMLs where $43 \mathrm{kA} / \mathrm{mm}$ was given as the maximum recommended linear current density. Currently, a similar study [11] for convex-shaped rails has not been investigated. Therefore, $35 \mathrm{kA} / \mathrm{mm}$ was taken as an assumption.

The peak value of current distribution in the convex rails decreases with an increase in the separation, as presented in Fig. 7. The decrease is due to decreasing proximity effect. Moreover, since heat conduction was assumed to be zero, the maximum temperature change in rails with higher separation will definitely be lower. This article aims to find the optimum separation with maximum projectile exit kinetic energy. However, if the maximum temperature were to be an element of our cost function, the optimum separation would surely be higher than our optimum.

According to Fig. 11, the kinetic energy of the launch package increases with an increase in separation. When we increase the area between the rails, the inductance gradient $L^{\prime}$ increases and the force applied on the launch package increases. However, the kinetic energy of the projectile has an inverse parabolic shape where there is an optimum point where the maximum point was selected as our optimum. However, from a mechanical point of view, in order to decrease the maximum temperature change and rail pressure, increasing the separation may be suitable with a slight compromise on the overall input to projectile efficiency.

\section{CONCLUSION}

In this article, a convex rail geometry optimization procedure is explained and an optimum rail geometry is determined for a rail with small/medium caliber with 40-mm height. The procedure involves not only the projectile mass but also parasitic sabot petals and $\mathrm{C}$-shaped armature mass. The optimization aims to maximize the exit velocity of the projectile and hence maximize the overall EML efficiency while minimizing the inner surface current density to decrease ohmic losses. The optimization has two parts. A 2-D FE model is built to find the optimum convex rail geometries for different rail separations that are determined. Then, armature and sabot petal masses are calculated for each separation value. Finally, using the total mass, a 3-D FE model is repeated for different separations to find the optimum rail length, the kinetic energy of the projectile, and hence the efficiency. The optimum rail separation is chosen according to the exit velocity of the projectile. The length of the rail is determined such that the armature exits the muzzle at $80 \%$ of the peak current at the current ramp-down stage to prevent transition. The final results are given in Table IV. Some comments about the overall analysis are as follows.

1) Changing the convex rail geometry parameters, a uniform current density distribution is achieved at the inner surface of rails. Therefore, a better heat distribution, less ohmic loss, less heat generation, and higher contact area can increase system efficiency and mechanical stability.
Moreover, the rail-armature contact transition can be avoided.

2) $b$ parameter converges to the same value for each separation. The significant parameter for convex rails for different separations is $a$ parameter. Therefore, it should be calculated carefully.

3) It is known that $L^{\prime}$ increases with increasing rail separation and, hence, a higher force acts on the armature. However, as separation increases, the parasitic mass also increases. According to study results, an optimum rail separation exists for maximum exit velocity of the launch package that also corresponds to maximum input to projectile efficiency point.

In this article, the effect of VSE on the current distribution was neglected. The same trapezoidal current waveform was assumed for each separation. Moreover, armature and sabot petal geometries were not optimized. As future work, this procedure can be repeated with VSE effects and a model-integrated PPS using a much better armature and sabot petal designs.

\section{ACKNOWLEDGMENT}

The authors would like to thank Mustafa Karagöz, Baran Yıldırım, and İbrahim Güngen for their support and collaboration.

\section{REFERENCES}

[1] R. A. Marshall, "Railgun bore geometry, round or square?" IEEE Trans. Magn., vol. 35, no. 1, pp. 427-431, Jan. 1999.

[2] R. L. Ellis, J. C. Poynor, B. T. McGlasson, and A. N. Smith, "Influence of bore and rail geometry on an electromagnetic naval railgun system,' IEEE Trans. Magn., vol. 41, no. 1, pp. 182-187, Jan. 2005.

[3] P. Zuo, J. Li, X. Song, and J. Yuan, "Characteristics of current distribution in rails and armature with different section shape rails," IEEE Trans. Plasma Sci., vol. 41, no. 5, pp. 1488-1492, May 2013.

[4] L. Jin, B. Lei, Q. Zhang, and R. Zhu, "Electromechanical performance of rails with different cross-sectional shapes in railgun," IEEE Trans. Plasma Sci., vol. 43, no. 5, pp. 1220-1224, May 2015.

[5] D. Feng et al., "Simulations on arc surfaced C-shaped armatures for round-like bore railguns," IEEE Trans. Plasma Sci., vol. 41, no. 5, pp. 1467-1474, May 2013.

[6] X. Wan, J. Lou, J. Lu, and D. Liang, "Thermal analysis in electromagnetic launcher with different section shape rails," IEEE Trans. Plasma Sci., vol. 46, no. 6, pp. 2091-2098, Jun. 2018.

[7] J. P. Barber, D. P. Bauer, K. Jamison, J. V. Parker, F. Stefani, and A. Zielinski, "A survey of armature transition mechanisms," IEEE Trans. Magn., vol. 39, no. 1, pp. 47-51, Jan. 2003.

[8] Y. Zhang, J. Ruan, J. Liao, and K. Liu, "Effect of geometry change on solid C shaped armature," in Proc. 16th Int. Symp. Electromagn. Launch Technol., May 2012, pp. 1-5.

[9] T. Watt and F. Stefani, "The effect of current and speed on perimeter erosion in recovered armatures," in Proc. 12th Symp. Electromagn. Launch Technol., May 2004, pp. 429-434.

[10] S. Hundertmark, M. Schneider, D. Simicic, and G. Vincent, "Experiments to increase the used energy with the PEGASUS railgun," IEEE Trans. Plasma Sci., vol. 42, no. 10, pp. 3180-3185, Oct. 2014.

[11] F. Stefani and R. Merrill, "Experiments to measure melt-wave erosion in railgun armatures," IEEE Trans. Magn., vol. 39, no. 1, pp. 188-192, Jan. 2003.

[12] S. Satapathy and H. Vanicek, "Down-slope contact transition in railguns," IEEE Trans. Magn., vol. 43, no. 1, pp. 402-407, Jan. 2007.

[13] D. Ceylan, M. Karagoz, Y. Cevik, B. Yildirim, H. Polat, and O. Keysan, "Simulations and experiments of EMFY-1 electromagnetic launcher," IEEE Trans. Plasma Sci., vol. 47, no. 7, pp. 3336-3343, Jul. 2019.

[14] L. Tang et al., "Optimizing study on the concave arc surfaced C-shaped armature with medium and small calibers," IEEE Trans. Plasma Sci., vol. 43, no. 5, pp. 1136-1141, May 2015. 


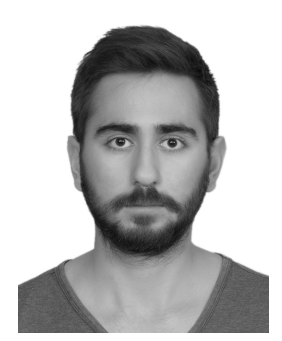

Hakan Polat received the B.Sc. degree from the Department of Electrical and Electronics Engineering, Middle East Technical University (METU), Ankara, Turkey, in 2018, where he is currently pursuing the M.Sc. degree.

His current research interests include electromagnetic launchers, pulsed-power sources, renewable energy, and wireless power transfer.

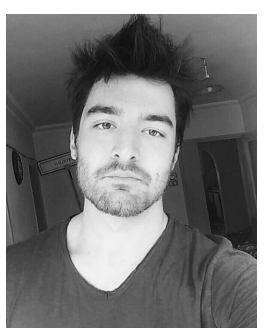

Nail Tosun received the B.Sc. degree from the Department of Electrical and Electronics Engineering, Middle East Technical University (METU), Ankara, Turkey, in 2019, where he is currently pursuing the M.Sc. degree.

His current research interests include electromagnetic finite element method (FEM) analysis, optimization of electrical machines, and power electronics.

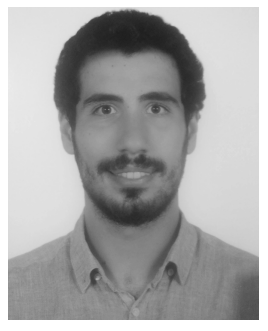

Doğa Ceylan received the B.Sc. and M.Sc. degrees from the Department of Electrical and Electronics Engineering, Middle East Technical University (METU), Ankara, Turkey, in 2016 and 2018, respectively. He is currently pursuing the Ph.D. degree with the Electromechanics and Power Electronics Group, Eindhoven University of Technology, Eindhoven, The Netherlands.

His current research interest focuses on the design and optimization of electrical machines, electric vehicles, and electromagnetic launchers.

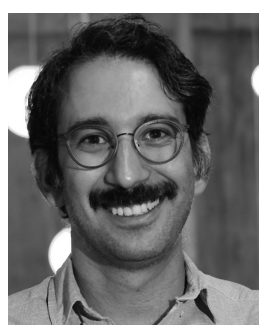

Ozan Keysan received the master's degree from Middle East Technical University (METU), Ankara, Turkey, in 2008, and the Ph.D. degree from The University of Edinburgh, Edinburgh, U.K., in 2014.

$\mathrm{He}$ is currently an Assistant Professor with the Electrical and Electronics Engineering Department, METU. His current research interests include renewable energy, design and optimization of electrical machines, smart grids, superconducting machines, and permanent-magnet machines. 